\title{
Dwergmuishondjies en die betekenis van Golgota? Enkele teologiese en ekologiese perspektiewe
}

J A du Rand

\section{ABSTRACT}

Dwarf mongooses and the meaning of Golgotha? Some theological and ecological perspectives

During the previous eight years we have taken notice of growing theological reflection on the ecological meaning of God, creation and re-creation. It seems that an holistic view of God, man and environment in a balanced coherence leads to a level-headed environment ethics. In this contribution the question is discussed whether Christianity with its exclusive views on man have not contributed to the harmful affliction of the ecological consciousness by subordinating the place and meaning of creation to salvation. An effort is made to prove, mainly from the creation stories, Romans 8 and Colossians 1, that creation and salvation should be seen as different meaningful moments of the same process through which God reveals Himself to mankind. Creation and salvation have positioned man as a "new" being with a new responsibility to take care of the nun-human part of creation which also includes dwarf mongooses.

\section{AANLEIDING EN DOEL}

'n Mens hoef nie retories breedsprakig te raak om die nuuskierige pienkneus dwergmuishondjie (helogale parvula) in verband te bring met die betekenis van die gebeure by Golgota en die leë graf nie. God het die hele skepping - ook die niemenslike deel - in gedagte gehad toe Hy sy Seun gestuur het om almal en alles te vernuwe. En dié nuwe lewe wat deur die Seun se verlossingsdaad bewerk is, werk vernuwend deur om almal en alles betekenisvol te raak. Tussen Skepper en skepsel het 'n nuwe verhouding tot stand gekom. Die bevryde nuwe mens kyk nou deur'n nuwe bril na God, maar ook na sy omgewing met 'n nuwe verantwoordelikheidsbesef. Dit laat die mens klein voel om deel te mag wees van só 'n groot skepping, maar dit laat hom/haar ook groot voel om God se plaaslike agent in sy herskepping te wees. Ons nuwe besig-wees met God se skepping raak ook die dwergmuishondjies as voorbeeld van die nie-menslike werklikheid om ons.

Die aanleiding tot die skryf van dié artikel is drieërlei van aard:

Eerstens, 'n weeklange boskamp in die Nasionale Krugerwildtuin wat ten doel gehad het om elke deelnemer weer só na as moontlik aan die natuur te bring, het 'n mens snags op 'n grondbedjie onder 'n maroela en die wakende oog van die melkweg sterre, teen die agtergrond van die gebrul van leeus en die skril roep van 
die naguiltjie, diep laat nadink oor God, sy skepping, die herskepping en die mens se plek in dié groot tapisserie van sy genade.

Tweedens, veral gedurende die afgelope dekade het belangwekkende teologiese denke oor ekologie neerslag in Suid-Afrikaanse geskrifte gevind ${ }^{1}$. Dié bydraes het nie net stimulerende denke geprikkel nie, maar ook meegewerk daartoe dat 'n verwaarloosde gebied op teologiese terrein opnuut en eietyds onder die soeklig kom.

Derdens, die Aardeberaad in Rio de Janeiro, gedurende Junie 1992, as opvolging van die Stockholm-konferensie in 1972 en die Assisi-verklarings van 1986, het omgewingsbewustes gaande gehad - 178 lande is verteenwoordig deur leiers en 8000 afgevaardigdes, en vyf ooreenkomste is onderteken. Die klem het veral geval op finansiële steun om ontwikkelende lande te help om in hulle oorlewingstryd nog die omgewing te bewaar ${ }^{2}$.

Onderliggend aan bogenoemde aanleiding is deurgaans die vraag na die mens se rol en roeping ten opsigte van die skepping. Deur die Christusgebeure het God 'n nuwe vennootskap met die mens gesluit. Daarom is dit die doel dat teologie duidelike Skriftuurlike perspektiewe moet trek om die moderne geloofsmens se oë te open vir 'n lewensingesteldheid van sensitiwiteit teenoor die omgewing.

Die mens en sy omgewing is saam oppad na God se voleinding toe. In dié proses moet ons soek na balans om altyd ons vooruitgang te toets aan God se perspektief op ons wetenskapsontploffing en kennis. Die natuur moet as God se skepping raakgesien word. Die Christen se geloof het nie net betrekking op eie verlossing en vertikale asemhaling nie, maar ook op die horisontale kosmiese ineengevlegtheid met die natuur. Dit beteken dat ons ekologiese bewussyn nooit slegs op oorlewing ingestel mag wees nie, maar altyd op 'n soeke na die eer van God. God se skepping is immers ook sy genade-akker waar ons daagliks leef en werk. Die moderne mens kan nooit te veel aan dié werklikheid herinner word dat interafhanklikheid en 'n nuwe verantwoordelikheid noodsaaklike ekologiese uitgangspunte is nie.

\section{2}

\section{EKOLOGIESE AKTUALITEIT EN PROBLEMATIEK}

Ekologie (Grieks: ouxos oikos: huis; גoyos logos: leer) as wetenskap hou hom besig met die bestudering van die totale huishouding of omgewing, dit wil sê die interafhanklikheid tussen lewende organismes en die fisiese omgewing, terwyl ekologie as verskynsel te doen het met die ingewikkelde struktuur en wisselwerking tussen organismes en omgewing in 'n dinamiese ewewig. Wanneer dié ewewig as basis van biologiese voortbestaan versteur word, ontstaan ' $n$ ekologiese krisis ${ }^{3}$. Dit kom aan die lig wanneer die natuurlike bestaansvoorwaardes van 'n ekosisteem, dit is die eenheid tussen omgewing en lewende organismes versteur word, soos wanneer 
water en lug byvoorbeeld besoedel word.

In diê versteuringsproses is die mens die grootste sondebok: riviere, oseane en die lug word besoedel; plante en diere word uitgeroei en hulpbronne uitgeput. Dit is egter ook die mens wat deur bewaring en bestuur die gebruik van die biosfeer kan bepaal om aan toekomstige geslagte 'n menswaardige bestaan na te laat. Deur sy tegnologiese greep op die natuur staan die mens midde-in 'n omgewingskrisis. Dit sou egter eensydig wees om die mens net te veroordeel. In sy angstigheid om as God se verteenwoordiger oor die natuur te heers, het selfsug en ongehoorsaamheid as direkte gevolge van die sondeval die mens oorweldig. Daarom is dit ook waar dat die mens wat nuut geword het in Jesus Christus sy heerserstaak oor die natuur ook nuut sal verstaan. Die akute ekologiese krisis raak dus ook die teologie, dit wil sê ons nadenke oor God, sy skepping en sy herskepping, waarvan ons deel is.

In ekologiese nadenke is ' $n$ definitiewe teologiese uitgangspunt noodsaaklik. Die Christen se nuwe uitsig op God as Verlosser bring ook nuwe insig ten opsigte van die werklikheid en die omgewing. 'n Holistiese siening waarin God, mens en omgewing in 'n ordelike samehang funksioneer, lei tot 'n omvattende omgewingsetiek ${ }^{4}$. God se handelinge by Golgota en die leë graf omspan dus die totale werklikheid. Die mens sien homself as deel van dié totaliteit. Deur die belydenis dat dit God se totaliteit is, aanvaar die Christen onmiddellik die verantwoordelikheid vir 'n konstruktiewe betrokkenheid by die natuur in sy omvattendheid. Deur 'n holistiese benadering word die mens se etiese blikveld verbreed om kosmies te dink en nie net antroposentries nie. As nuwe mense in Christus is ons belangrike deelnemers aan God se voortgaande skeppingsproses.

3

IS DIE CHRISTENE SKULDIG?

Die Christendom is sedert die sestigerjare daarvan beskuldig dat hy ' $n$ agent is vir die verwydering tussen die mens en die natuur, en daarom die blaam moet dra vir Christene se interpretasie van Genesis 1:26, 28 om oor die natuur te heers, het volgens die aanklag ontaard in 'n respeklose plundering van die omgewing. Mens en natuur is van mekaar verwyder en die natuur is gesien as blote gebruiksmiddel van die mens. Op só 'n wyse is die natuur ontgoddelik en het dit bloot 'n ding geword wat ontleed en ontgin is. Die Christendom sou dan deur sy monoteïstiese ondertoon 'n dualisme tussen mens en natuur bewerk het. White stel dit só: "Especially in its Western form, Christianity is the most anthroposentric religion the world has seen"6.

Die skepping is gerelativeer ten gunste van verlossing?. Sodoende het die natuur ' $n$ ondergeskikte posisie teenoor die mens ingeneem en is dit as onbelangrik 
uit die teologie uitgeskryf. Die Christendom is selfs daarvan verwyt dat hy ongeërg gestaan het teenoor geboortebeperking om sodoende die vrug van ekologiesoorlaaide bevolkingsontploffings te pluk. Tot sover die aanklag teen die Christendom.

Dit is egter totaal eensydig om die ekologiese krisis slegs op rekening van die Christendom te plaas. Is dit nie eerder só dat die sogenaamde kultuuropdrag in Genesis 1:26, 28 verkeerd geïnterpreteer is vanweë die sondeval nie? Wanneer teologie eensydig antroposentries of soteriologies afgestem is, kan 'n mens maklik perspektief op die geheel van die skepping verloor. Die natuur is beslis nie heilig of goddelik soos sommige godsdienste dit stel nie. Die heers oor die natuur mag ook nooit 'n vernietiging van die natuur inhou nie, maar moet nuut gedefinieer word vanuit die vernuwing wat God deur Jesus Christus bewerk het. Verlossing en skepping staan nie teenoor mekaar nie, maar kom uit die hand van dieselfde God. Dit is wel belangrik dat verlossing en die effek daarvan breër gedefinieer moet word om ook die hele skepping te betrek by God se heilsbedoeling. In dié proses is en bly die mens die sentrale agent wat God se bedoeling bekend moet mak. Dit is juis die Christenmens, geskape na die beeld van God, wat met 'n nuwe hand en hart moet uitreik na die natuur toe. Die spanning tussen mens en natuur hoef nie en behoort ook nie volgens Skriftuurlike gronde te lei tot ekologiese wanopvattings nie.

DIE MENS EN SY LEEFWARELD

Met die oog op 'n gefundeerde besinning oor die Christen se ewewigtige verhouding met God en die wêreld, moet ons eers kortliks stilstaan by die moderne mens in sy huidige leefwêreld. 'n Volledige oorsig kan dit uiteraard nie wees nie. 'n Algemene tipering van die moderne mens wat hom/haar in 'n ekologiese krisis bevind, word beperk tot die Westerse denke van kapitalisme ${ }^{8}$. Dié mens se lewensingesteldheid word grotendeels bepaal deur die tegniek as sy vermoë om die omgewing te beheers. Dié tegniek kan die mens se solidariteit met sy ekologiese samehang respekteer of minag.

Sedert die industriële rewolusie van die 18 e en 19 e eeu sien die mens homself as heerser van die natuur wat dit maar kan manipuleer. Die natuur word nie met eerbied bejeën nie, maar moet ombou word tot nut van die mens. Daarom is dit noodsaaklik dat die teologie die mens se verhouding met die nie-menslike opnuut Skriftuurlik moet herdefinieer.

Onder die vaandel van ontwikkeling laat die moderne mens hom lei deur 'n onuitputbaarheidsdenke en 'n benutbaarheidshouding' ten opsigte van die aarde. Die nuttigheid van grondstowwe word byvoorbeeld baie hoog geag, so asof dit onbeperk ontgin kan word. Die omgewing word hoofsaaklik ter wille van die mens se vooruitgang aangewend. Die uitsterf van dier- en plantspesies en die vernietiging 
van ekosisteme deur bevolkingsontploffings illustreer dié benadering van die mens slegs ter wille van die mens. Tegnologiese vooruitgang moet egter deurgaans rekening hou met ekologiese ewewig. Die kosmiese mag nooit net gesien word as die arena vir vooruitgang en produksie nie. God se aarde moet skeppingswaardig bejeën en bewoon word.

In die twintigste eeu sien die moderne mens homself as outonoom en hy/sy bou strukture deur die politiek, industrieë en militêre aktiwiteite wat dikwels omgewingsvernietigend is (bv brandende olievelde van Irak). In dié proses word God buite die denkwêreld geprojekteer as die transendente wat afwesig is van sy skepping. Dit is nie waar nie. Natuurromantiek is egter net só onaanvaarbaar as natuurveragting. Ons kan nie terugkeer na 'n oerlewe in die natuur nie, maar moet met 'n nuwe lewensingesteldheid betekenisvol met die natuur omgaan.

'n Eensydige siening dat die mens eintlik 'n bonatuurlike verlossingsbestemming het, lei daartoe dat die kosmiese en ekologiese bewussyn in die slag bly. Verlossing en skepping staan nie teenoor mekaar nie, inteendeel, die versoenende rol van die verloste teenoor die natuur illustreer juis dat God sy doel bereik het.

Die moderne mens het tot 'n groot mate verkneg geraak aan arbeidsvergoding ${ }^{10}$ met die klem op ekonomiese groei ongeag hulpbronuitbuiting. Ter wille van voorspoed het die mens ondergeskik aan sy arbeid geword - kompetisienajagend. Werk is lewensnoodsaaklik, maar moet ewewigtig binne God se omvattende bedoeling perspektief kry.

'n Ongebalanseerde soeke na geborgenheid in welvaart en vooruitgang kan God en sy bedoeling nie raaksien nie. Ons beleef tans 'n tydvak van ongekende materiële welvaart aan die een kant, maar ook ongekende materiële armoede en ellende aan die ander kant. Solle ${ }^{11}$ sê dat tegnologie vir die moderne mens die almagtige surrogaat vir God geword het. Gewaande selfstandigheid het die mens losgemaak van sy Bron. Dit laat 'n mens vir jouself skrik.

Wetend en onwetend is die moderne mens in sy opmars na voorspoed besig om lewensvernietigend in plaas van versoenend met die natuur om te gaan. Ekologiese ewewigversteuring word veral versnel deur eksponensiële bevolkingsgroei, die uitputting van die aarde se hulpbronne, 'n besoedelingsprobleem (osoonlaag, suurreën, riviere) en onkontroleerbare beskawingsdruk ${ }^{12}$. Hieber benadruk veral drie aspekte: geweld, onreg en natuureksploitasie ${ }^{13}$. Saamgevat: welvaartsdruk het 'n god geword. Die vraag word al hoe ernstiger gevra of ons nie op sosiale, politieke, ekonomiese en godsdienstige front daarna moet streef om 'n zero bevolkingsgroei dwarsoor die aardbol te bewerkstellig nie.

Alhoewel die mens die hoofvernietiger van sy omgewing is, is hy ook die omgewingsbestuurder wat die ekologiese omkeer kan bewerk. Deur wetenskaplike en tegniese vindingrykheid is dit juis die mens wat ekologiese ewewig kan probeer herstel om geregtigheid, vrede en vervulling te bring. 'n Fyn wisselwerking tussen 
ekonomiese ontwikkeling, lewenskwaliteit en omgewingsgesondheid moet ontwikkel word op nasionale en internasionale vlak. Ons kan tog nie terugkeer tot 'n heidense panteïsme of animisme toe harmonie tussen mens en natuur geheers het nie. 'n Teologies gemotiveerde gesindheidsverandering kan egter weer ekologiese ewewig herstel sodat ook die dwergmuishondjie daarby baat.

\section{OM TOT 'N TEOLOGIESE ANTWOORD TE KOM}

Dit is 'n algemene verskynsel dat die teologiese denke tot betreklik onlangs geisoleerd gestaan het ten opsigte van natuurwetenskaplike ekologiese aangeleenthede. Besinning oor die Christelike belydenis het nagelaat om die mens se verantwoordelikheid teenoor die skepping as sodanig uit te spel. Omgewingsbewaring moet gesien word as die sigbaar word van die nuwe mens in Christus se geloof. Enkele gevolgtrekkings oor Bybelse waarhede uit die Ou- en Nuwe Testament is ter sake, met meerdere toespitsing op die skeppingsbeginsel en dele uit Romeine en Kolossense.

Teologiese refleksie oor die Ou- en Nuwe Testament rakende ekologie het verskuif vanaf 'n antroposentriese en soteriosentriese fokus na 'n meer gebalanseerde kosmosentriese denke ${ }^{14}$. Die Skrifboodskap word as 'n organiese geheel gelees waar skepping, sondeval, verlossing en eskatologie 'n eenheid vorm.

Die Ou-Testamentiese mens dink hoofsaaklik vanuit 'n skeppingsraamwerk wat ook die kosmiese, politiese en sosiale insluit ${ }^{15}$. God het alles geskape en heers ordelik daaroor. Binne dié Godgeskape orde moet die mens betekenisvol leef. Geregtigheid word byvoorbeeld nie net gesien as 'n regsbeginsel nie, maar deel van God se wêreldorde waarbinne mens en skepping in ewewig behoort te leef. Ons leef binne God se voortgaande skeppingsonderhouding en tree op as sy agente. Die mens moet dus nie apart van die res van die skepping gesien word nie. Alles en almal het 'n gemeenskaplike herkoms in die Skepper, God. Om dié rede moet die hele skepping in relasie tot God oriënteer en leef (Ps 148).

Die mens as beeld van God (Gen 1:26) is funksioneel heerser en verteenwoordiger van God in die skepping - geroep tot diens en nie tot selfsugtige selfverryking nie. Natuurwetenskaplike navorsing word daarmee nie onbelangrik nie, maar moet juis binne die raamwerk van diens en verantwoordelikheid plaasvind. Dan is beeldskap nie 'n statiese eienskap nie, maar die dinamiese relasiebelewing met God en die natuur binne dieselfde ruimte wat God daarvoor bestem het. My vredeliewende heerskappy oor byvoorbeeld dwergmuishondjies - as verteenwoordiger van die Skepper - sê tegelyk iets oor my verhouding as mens tot God. Die natuur word nie daardeur vergoddelik nie maar bewerk vanuit Goddelike perspektief. Le Roux sê ons is God se onderkoning op aarde ${ }^{16}$. Die betekenisvolle saambestaan van die mens in God se ekostelsel vereis veral 'n dienstaak. As 
klimaks van God se skeppingsdade is die bestaan van die mens gerig op die hele skepping.

Die Ou Testament leer veral dat die mens deel is van die totaliteit van die skepping en dat hy/sy ook met vryheid van keuses verantwoordelik is vir die skepping. Mens, dier en plant deel in God se voortgaande skeppingsonderhouding. Arbeid is daarom nie net negatief te beskou as straf nie, maar as verantwoordelike bestuur van die skepping. Die Ou Testament herinner ons daaraan om die skepping vanuit die Godperspektief raak te sien.

Die sentrale boodskap van die Nuwe Testament handel oor die verlossing en lewe wat gekom het deur die menswording van Jesus Christus. Die Nuwe Testament beklemtoon dat God as Skepper in beheer bly van sy skepping en dat $\mathrm{Hy}$ deur die herskepping daarvan deur Jesus Christus almal en alles laat afstuur op sy bedoelde einde (Rom 2). In Jesus Christus het God alles nuut gemaak, 'n nuwe skepping ( 2 Kor 5:7), en het die nuwe era reeds aangebreek. Die klem op 'n gerealiseerde eskatologiese denke het verrykende implikasies vir 'n Nuwe-Testamentiese ekologiese bewussyn. Dit beteken dat die Christene nou reeds as nuwe mense in God se nuwe era leef. Die verwagting en die uitsien dat God uiteindelik alles in alles sal wees, neem egter nog 'n belangrike plek in (1 Kor 15:28).

In Romeine 8:18-30, veral verse 18-22, gee Paulus duidelike kosmiese perspektiewe op die implikasies van die verlossing wat in Jesus Christus gekom het. Die tema van die paragraaf is in vers 18 vervat: uitsig op God se heerlikheid in die toekoms. In verse $19-22$ val die klem op die hele skepping wat uitsien na dié toekoms wanneer God bekend mak wie sy kinders is, maar ook wanneer die skepping bevry sal word van sy "verslawing aan die verganklikheid" (Rom 8:21), terwyl hy nog aan "verydeling onderworpe" is (Rom 8:20). Die skepping is bestem om God se heerlikheid te vertoon, maar gaan gebuk onder 'n vergeefsheid (verydeling) as gevolg van die sondeval. Die hele skepping, wat die mens insluit, sien gevolglik hartstogtelik uit na die volle herstel van die bereiking van die Goddelike bedoeling. Indien die skepping met 'n klavier vergelyk kan word, sou 'n mens kon sê dat die skepping sy klank behou het, maar dat sy klink (dit wil sê toonhoogte) van toon af is in die verkondiging van die heerlikheid van God. Dit word eers by die voleinding volmaak herstel.

Paulus laat die fokus nogeens daarop val dat die mens en die res van die skepping ten nouste aan mekaar verbonde is. Deur die mens se keuse vir sonde is die hele skepping onder die vloek van die sonde geplaas. Mens en natuur ly saam onder die smet van sonde en ondervind die aantasting pynlik. Dit is egter net so seker dat die hele skepping ook deel in die verlossing wat Jesus Christus gebring het. Deur die krag van die Gees word die mens herskep met die deurwerking daarvan ook na die natuur. Alhoewel die volmaakte nog nie aangebreek het nie, is die mens en natuur reeds binne die raamwerk van God se herskepping daarheen op 
pad. Die geskiedenis van mens en natuur is daarom Geestelik ineengestrengel ${ }^{17}$. Die hele skepping het hoop ( $v 19)$ op grond van die vaste gronde dat Christus verlossing bewerk het. Die Christosentriese verlossing in die verloop van die kosmiese geskiedenis moet nooit misgekyk word nie. Gibbs vat dit raak saam deur te sê dat Paulus die totale sfeer van die werklikheid vanuit Christus se holistiese Heerskap besien ${ }^{18}$. Is dit nie treffend nie: mens en natuur staan solidêr met mekaar ten opsigte van die hede en toekoms op grond van die Christusgebeure. Dit beïnvloed ons ekologiese denke, om daarmee rekening te hou dat die totale skepping deel is van God se verlossingsgeskiedenis. Dit bring ook mee dat die nuwe mens met groter respek sy wetenskap en tegniek sal toepas op sy lotsgebonde genoot, die natuur. Saam ly ons en saam hoop ons op grond van Jesus Christus se kosmiese Heerskap.

In Kolossense 1:15-20 word Christus as die skeppings- en verlossingsmiddelaar besing. Verse 15-18 fokus op Christus in sy skepperfunksie en verse 1920 op die Seun van God in sy verlosserfunksie. Dit is opvallend dat skepping en verlossing in die persoon en funksie van Christus saamgebind word. Baugh meen tereg dat ons in Kolossense 1:15-20 met 'n chiastiese opbou te doen het waarin vers 17 die draai-as vorm: "en deur Hom bly alles in stand"19. Die Seun staan in 'n besondere verhouding tot God (v 15). Deur Hom word God teenwoordig. Hy staan ook in 'n besondere verhouding tot die skepping - die Eerste en verhewe bo die hele skepping ( $\mathrm{v} 15 \mathrm{~b}$ ). Die Seun is pre-eksistent en is as Verlosser reeds in die skepping veranker. Christus is die oorsprong en doel van die skepping en beklee dit as Middelaar (v 16). Alles en almal is geheel en al afhanklik van Christus. Deur Hom het dit ontstaan en deur Hom bestaan alles voort. Hy onderhou alles. God is steeds aan die werk in sy skepping ( $v$ 17) en hou dit in stand deur sy Seun. In Jesus Christus word almal en alles wat bestaan saamgebind. Om dié rede is Hy deur sy versoenende sterwe dié Een deur wie almal en alles hulle Goddelike doel bereik ( $v$ 20). Deur Hom stig God die nuwe mensheid - die verloste mensheid ${ }^{20}$. Jesus Christus is die versoening, die brenger van vrede (v 20). In Hom is die, as gevolg van sonde, gebroke verhouding herstel. Die versoenende boodskap van die kruis het daarom 'n skeppingseffek. Die plaasvervangende sterwe van Jesus Christus verbind skepping en herskepping met ekologiese implikasies.

Sou 'n mens dié lied in Kolossense 1 die belydenislied van die moderne wetenskaplike kon noem? Dis 'n geloofsuiting om te sê dat Jesus Christus die Middelaar by die skepping en herskepping is. Die effek van verlossing realiseer verder deur bemiddeling van die belydende Christenmens. Sonde veroorsaak dat ons die skepping van God misverstaan. Verlossing het weer ons oë geopen om as nuwe mense opnuut betrokke te wees met verantwoordelikheid by die hele skepping - ook by die ekologies ewewigtige bestuur van byvoorbeeld dwergmuishondjies as deel van die nie-menslike skepping. 
Die mens wat bevry is van die gevolge van sonde moet Christus se oorwinning sigbaar leef sodat die hele skepping die vrug daarvan kan pluk. Dit beteken dat God se geskapenheid in hulle volle funksie tot hulle Godbedoelde reg moet kom. Die vertikale versoening moet ook sigbaar word tussen mens en medemens, en ook in die mens se verantwoordelikheid tot die nie-menslike skepping. Dit hou in dat die Christen-wetenskaplike sy/haar verlossing vier deur 'n besondere verantwoordelike omgaan met die nie-menslike.

\section{6}

\section{'N SLOTWOORD}

Die Christen se ekologiese feesviering vloei voort uit sy/haar bewussyn dat God geskep het en deur Jesus Christus herskep het. God, mens en skepping het deur die versoenende kruisdood van Jesus Christus by Golgota in 'n nuwe verhouding te staan gekom wat die hele skepping raak. Die navorsing in die laboratorium en die eksperimente in die ekosisteem dra nou die waarmerk van 'n belydenis: God is skepper en in Jesus Christus herskepper en Hy onderhou sy skepping deur agente wat totaal nuut geword het. Die hele skepping herinner die mens wat nuut geword het gedurigdeur daaraan dat die Skepper-God werklik bestaan en dat Hy steeds omgee omdat Hy ook verlos het - nie net mensesiele nie, maar die ganse skepping. Vir die nuwe mens het ekologiese wetenskapsbeoefening en bewaring 'n opwindende geloofservaring geword omdat die effek van die gebeure by Golgota verder strek as die mens. Dit roep 'n mens op om ook deur nuwe oë na God, jouself, die omgewing en die dwergmuishondjies te kyk.

\section{NOTAS:}

1 Let veral op die bydraes van J A Loader, "Image and order: Old Testament perspectives on the ecological crisis" in: Are we killing God's earth? Ecology and theology, (Edited by W S Vorster), Pretoria: UNISA 1987, 6-28; K Nürnberger, "Ecology and Christian ethics in a semi-industrialised and polarised society", in: Are we killing God's earth?, 45-67; D F Olivier, "'God's rest' the core and Leitmotif of a Christian holistic view of reality?", in: Are we killing God's earth?, 100-118; J Buitendag, Skepping en ekologie: 'n Sistematiese ondersoek na die teologiese verstaan van die werklikheid, (DDproefskrif), Universiteit van Pretoria 1985; J Buitendag, Die skepping as gelykenis: 'n Beoordeling van die skeppingsleer van Karl Barth in die lig van die appèl van die ekologiese krisis", HTS 42 (1986), 674-695; J Buitendag, "En nou bly Skepper, skepsel, skepping - hierdie drie: 'n Teologiese profiel van die ekologiese debat", HTS 44 (1988), 295-313; P G W du Plessis, "Environmental ethics of the future", Koers 53 (1988), 253-265; A J van der Walt, "The need for conservation of the built-up environment", Koers 53, 74105; B J Engelbrecht, "Teologie en ekologie", HTS 44 (1988), 23-38; C J P le Roux, Eko-teo-logie. Op soek na 'n eko-teo-logie vir die moderne tegnieker, 
(DD-proefskrif), Universiteit van Pretoria, Pretoria 1991.

2 Vergelyk M Grubb, "The road from Rio", The world Today 48 (1992), 140142, asook T Emerson, "The further road from Rio", Newsweek 25 (1992), 18.

3 Aldus J Buitendag, a w, 1988, 675; vergelyk R Dajoz, Introduction to ecology, London 1977.

4 D F Olivier, $a w, 1987,114$; vergelyk A J van der Walt, $a w, 1988,82$.

$5 \quad$ Seker die bekendste propageerder van die antyging is $L$ White, "The historical roots of our ecological crisis", Science 155 (1967), 1203-1207.

$6 \quad$ L White, $a w, 1967,1204$.

7 Die bekende standpunt van G von Rad, Old Testament Theology, Vol 2, Edinburgh 1966.

$8 \quad \mathrm{C} \mathrm{J} P$ le Roux, $a w$, lewer 'n verantwoorde en verteenwoordigende bespreking hiervan in hoofstukke 2 en 3.

$9 \quad$ Aldus C J P le Roux, $a w$, 1991, 70; vergelyk Du Plessis, $a w, 1988,258$.

10 J A Heyns, Teologiese Etiek 2/1: Sosiale Etiek, Pretoria 1986, 264; Kyk J A van Wyk, 'n Christelike etiek van arbeid, Pretoria 1988, 32.

11 D Sölle, Lieben und arbeiten. Eine Theologie der Schöpfung, Stuttgart 1987, 147; vergelyk C J P le Roux, $a$ w, 1991, 103.

12 B J Engelbrecht, $a w, 1988,31$.

13 W Huber, "Justice, peace and integrity of creation", Scriptura 24 (1988), 4. Kyk E J Mishau, "The economic growth debate: An assessment", London 1977.

14 Die standpunt van H P Santmire, The travail of nature: The ambigiuous ecological promise of Christian theology, Philadelphia 1984, 415.

15 Vergelyk H H Schmidt, "Schöpfung, Gerechtigkeit und Heil", ZThK 70 (1973), 2.

16 C J P le Roux, $a w, 1991,263$. Vergelyk J Barr, "Man and nature: The ecological controversy and the Old Testament", Bulletin of the John Rylands Library 55 (1972), 9-32.

17 Vergelyk H-F Weiss, "Schöpfung in Christus", Zeichen der Zeit 31 (1977), 434.

18 "Pauline cosmic Christology and ecological crisis", JBL 90 (1971), 471. Kyk P E Luz \& H P Santmire, Ecological renewal, Philadelphia 1972.

19 Kyk sy "The poetic form of Col 1:15-20", Westminster Theological Joumal 47 (1985), 235. 
20 In die woorde van P Pokorny, Der Brief des Paulus an die Kolosser, Berlin 1987,84 . 